\title{
PSYCHE.
}

\author{
ARKANSAS MELANOPLI. - II. \\ BY JEROME MCNEILL, FAYETTEVILLE, ARK.
}

Key to Melanoplus.

$\mathrm{A}^{1}$ Tegmina rarely shorter than the abdomen when much shorter the species are large, (more than one inch in length) and robust.

$\mathrm{B}^{1}$ Size large, never less than one inch in length usually much more, space between the eyes more than twice the width of the basal joint of the antennae, hind tibiae with a broad pale annulus (sometimes only apparent on the exterior face) preceded by a black sub-basal ring, median carina never obsolete upon the prozone, though often indistinct.

$\mathrm{C}^{1}$ Tegmina scarcely ever spotted and never striped on the anal field, hind tibiae and under surface of hind femora yellow, sides of prozone not expanding posteriorly $\quad . \quad . \quad . \quad . \quad . \quad . \quad . \quad . \quad$. $\quad . \quad$ Differentialis Uhler.

$\mathrm{C}^{2}$ Tegmina always maculate upon the discoidal field and frequently striped on the anal field, hind tibiae never yellow, either red or purplish, sides of the prozone plainly expanding posteriorly.

$\mathrm{D}^{1}$ Hind femora rarely banded on the disk of the outer face, tegmina usually exceeding slightly or considerably the hind femora, never much shorter than the abdomen, hind tibiae red or purplish . Bivittatus Say. $\mathrm{D}^{2}$ Hind femora generally very distinctly banded upon the disk of the outer face, tegmina much shorter than the abdomen, hind tibiae never purplish. $\quad . \quad$. $\quad . \quad . \quad . \quad . \quad . \quad . \quad$ Viola Thos.

$\mathrm{B}^{2}$ Size medium or small, space between the eyes not more than twice the width of the basal joint of the antennae, hind tibiae usually red without a pale annulus preceded by a black sub-basal spot or ring, rarely blue with the black followed by a pale ring, tegmina about equalling or more or less exceeding the abdomen.

$\mathrm{C}^{1}$ Second transverse sulcus of the pronotum not twice as distant from the third as from the first, tegmina very rarely falling short of the extremity of the hind femora. 
$\mathrm{D}^{1}$ Median carina of the prozone frequently indistinct but some trace of it is always present at least upon the anterior part of the prozone which is not distinctly longer than the metazone.

$\mathrm{E}^{1}$ Hind tibiae never red usually distinctly blue with the sub-basal black ring present and followed by a pale annulus or at least a pale spot exteriorly, transverse bands of the hind femora distinct upon the disk as well as upon the upper face; tegmina distinctly spotted on the discoidal field, with a linear series of alternate light and dark spots and generally less distinctly maculate with smaller spots upon the anal field.

Impiger Scudd.

$\mathrm{E}^{2}$ Hind tibiae never blue, usually red or green, occasionally with a black sub-basal ring but this is never followed by a light annulus.

$\mathrm{F}^{1}$ Sub-basal ring of the hind tibiae usually distinct, the tibiae themselves never green, tegmina obscurely spotted, sometimes slightly exceeding the hind femora but scarcely ever equalling the abdomen; black bands of the hind femora usually distinct, but sometimes confluent on the disk of the outer face; sides of the prozone expanding regularly and considerably; inferior branches of the ovipositor merely angulate upon the outer side not distinctly toothed. Keeleri Thos. $\mathrm{F}^{2}$ Sub-basal ring of the hind tibiae represented at most by a black or fuscous spot upon the upper face; tegmina generally exceeding the abdomen as well as the hind femora; inferior branches of the ovipositor with a distinct tooth upon the outer side.

$\mathrm{G}^{\mathbf{1}}$ Prosternal spine distinctly and regularly tapering upon the apical half with the apex sub-acute; median carina usually very indistinct upon the prozone, frequently almost entirely obsolete; tegmina generally distinctly spotted in the discoidal field; hind tibiae green or red. . . . . . . Atlanis Riley. $\mathrm{G}^{2}$ Prosternal spine not tapering upon the apical half, slightly transverse and broadly rounded at the tip, median carina generally distinct, through slight, upon the prozone, tegmina nearly plain or more or less distinctly spotted in the discoidal field, hind tibiae red, very rarely green. . . . Femur-rubrum De Geer.

$\mathrm{D}^{2}$ Median carina of the prozone entirely wanting, prozone plainly longer than the metazone; fascia of the hind femora obsolete upon the disk of the outer face; post-ocular stripe of the pronotum very' indistinct or wanting; tegmina plain or inconspicuously maculate; hind tibiae red or green. . . . . . . . . . Packardii Scudd. $\mathrm{C}^{2}$ Second transverse sulcus of the pronotum nearly twice as distant from 
the third as from the first and all are indistinct; tegmina scarcely reaching the hind femora, very obscurely spotted; no post-ocular stripe upon the head or lateral lobes of the pronotum; hind tibiae coral red with not a trace of a sub-basal black ring.

Impudicus Scudd.

$A^{2}$ Tegmina much shorter than the abdomen.

$\mathrm{B}^{1}$ Hind tibiae green.

$\mathrm{C}^{1}$ Tegmina separated by a space greater than their width. Gracilis Bruner. $\mathrm{C}^{2}$ Tegmina attingent or slightly overlapping. . . Sylvaticus n. sp.

$\mathrm{B}^{2}$ Hind tibiae red or fuscous.

$C^{1}$ Tegmina separated by a space much greater than the width of the frontal costa.

$\mathrm{C}^{2}$ Tegmina attingent or overlapping.

Obovatipennis Blatchley.

$\mathrm{D}^{1}$ Hind margin of the pronotum strongly angulate; tegmina decidedly longer than the pronotum and lanceolate. . . . Baconin. sp. $\mathrm{D}^{2}$ Hind margin of the pronotum slightly angulate; tegmina shorter than the pronotum, sub-elliptical in shape. . . . . . Scudderi Thos.

Melanoplus differentialis Uhler. - This species is apparently uncommon at least in the mountainous part of the State. It is represented in my collection by specimens from Washington, Sebastian. Crawford and Marion Counties. Two specimens from the last mentioned locality collected July twentieth differ rather remarkably from other specimens from Arkansas. They are very dull brown with considerable infuscations, the tegmina being darker in the lateral than in the dorsal field, irregularly clouded over both areas and maculate on the former. The disk of the prozone is distinctly longitudinal and about half as long again as the metazone. The hind femora are shorter than in typical specimens.

Melanoplus bivittatus Say. - This very variable species is rare in Northwestern Arkansas. I have collected but four males and two females. The males have uniformly red the females purplish hind tibiae. According to Scudder those with the red hind tibiae should be $\mathrm{Mel}$. femoratus Burm. but I am not able to recognize the distinctness of these supposed species. Two of the males were captured June twenty-sixth near War Eagle ford on the Spring Valley and Clifty road. Another male was taken near Clifty. The other specimens were captured at several points in Marion County from July tenth to twentieth.

Melanoplus viola Thos.-This species is abundant in Northern Arkansas and probably throughout the State in suitable localities, which are wooded hillsides and tops. I have thirty-one males and twenty-nine females from Washington, Carroll, Boone, Marion, Newton, Madison and Crawford Counties in the northwestern, and Pulaski 
and Jefferson Counties in the central part of the State. The earliest and latest date of its capture are June thirtieth and October twenty-sixth. According to Prof. Charles Wood worth, formerly Entomologist of the Arkansas Agricultural Experiment Station, at present of the University of California, this species sometimes lays its eggs in small holes in rocks in stone fences. It is a larger species than would appear from Scudder's measurements which are $25 \mathrm{~mm}$. for male and female. Average specimens in my collection measure as follows :

Length of body male, $25 \mathrm{~mm}$. female $32 \mathrm{~mm}$.

Length of hind femora male, $17 \frac{1}{2} \mathrm{~mm}$. female $\mathrm{r} 8 \mathrm{~mm}$.

The tegmina vary from one and a half times the length of the pronotum to the length (male) of the abdomen. The cerci are quite variable and the under side is frequently red as in $\mathrm{Mel}$. clypeatus Scudd. which is possibly only a synonym of Mel. viola.

\section{THE MOUTHPARTS OF THE NEMATOCEROUS DIPTERA, III.}

BY VERNON L. KELLOGG, STANFORD UNINERSITY.

\section{Dixidae.}

Dixa $s p$. The females of Dixa possess a mouth structure (see fig. 4) like those already described, consist- ing of labrum-epipharynx (fig. 4, l. ep), mandibles (fig. $4, m d$ ) which are short, weakly chitinized, trowel-shaped, with truncate, distal margin with fine, deep dentations ; maxillae (fig. $4, m x$ ) with 5 -segmented palpus and maxillar lobe weakly chitinized but long and conspicuous; strong labium (fig. 4, li) with free paraglossae and glossae fused to form a membranous

Fig. 4, Mouthparts of Dixa sp., $\$ ; ~ l . e p$ labrum-epipharynx, $m d$ mandible, $m x$ maxilla, $m x \quad l$ maxillar lobe, $m x . p$ maxillar palpus, $l i$ labium, $p g$ paraglossa, $g l$ glossa, hyp hypopharynx: median lobe; and hypophar$y n x$ (fig. 4, hyp) of usual type.

\section{Psychodidae.}

Psychoda sp. Psychoda (see

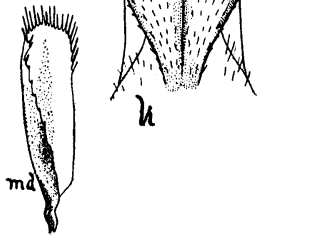

fig. 5) has no mandibles and the labium presents but two terminal lobes. The labrum-epipharynx (fig. $5, l$ l. ep) is short, broad, triangular. The maxillae (fig. 

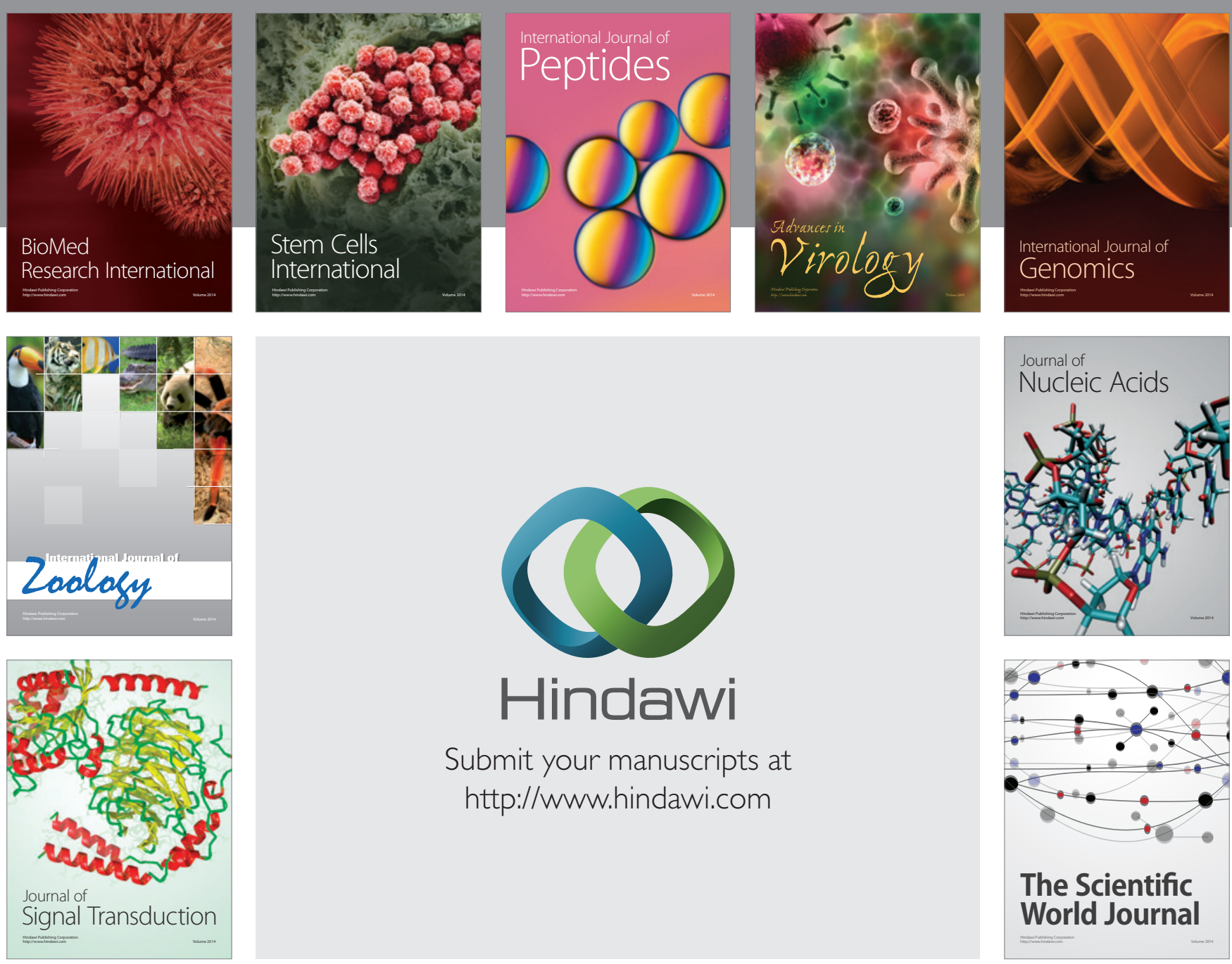

Submit your manuscripts at

http://www.hindawi.com
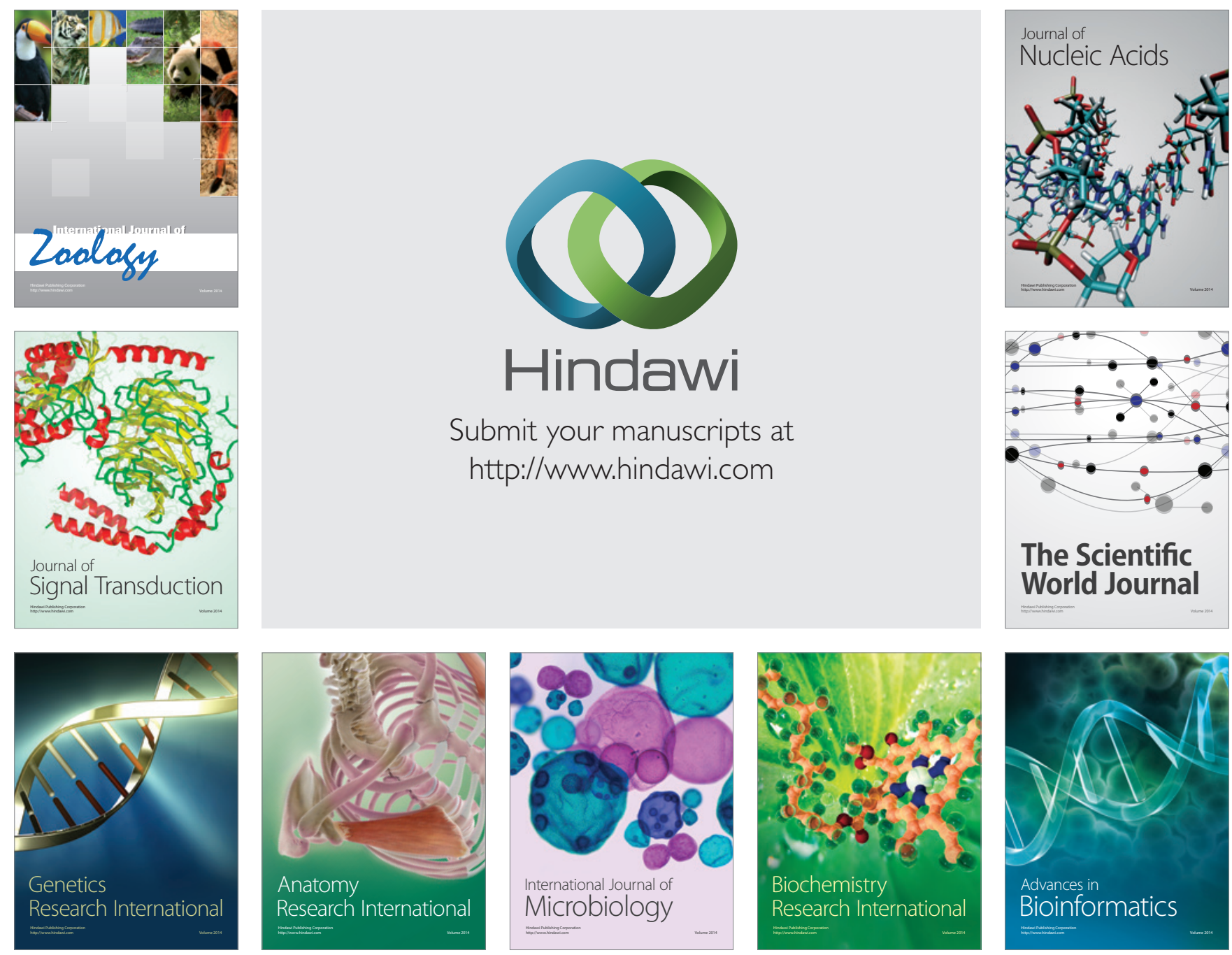

The Scientific World Journal
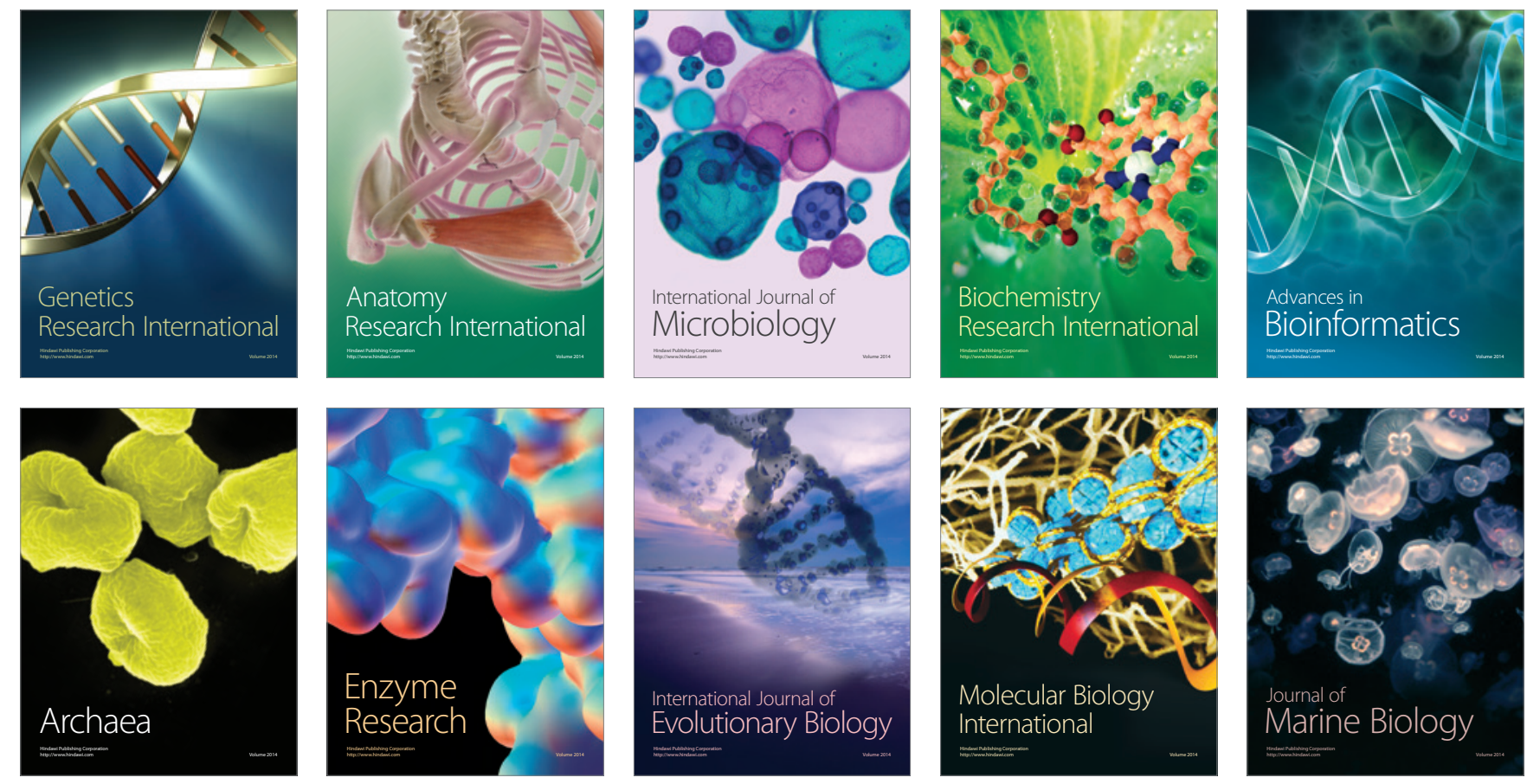